\title{
DEL SILENCIO DE LAS LENGUAS NATIVAS \\ A UN DESARROLLO RURAL TERRITORIAL \\ POLIITICAMENTE RENOVADO E INCLUSIVO
}

DOI: $10.5377 /$ rpdd.v6i1.12433

Recibido: agosto, 2021

\author{
NOEMÍ BORJAS ${ }^{1}$ \\ MARTA MAZIER $^{2}$ \\ MARCIA VALLADARES ${ }^{3}$ \\ GERARDO LAGOS ${ }^{4}$
}

Doctorandos en Ciencias del Desarrollo Humano, Universidad Nacional Autónoma de Honduras

\section{AGRADECIMIENTO}

Agradecemos la asesoría metodológica de la Doctora Margarita Oseguera y del Doctor Mario Samper

\section{INTRODUCCIÓN}

- ste artículo rescata los aportes del Foro Debate Contemporáneo del Desarrollo, Humano de la Facultad de Ciencias Sociales de la UNAH. Particularmente, se han retomado los debates del Círculo de Desarrollo Rural en dicho foro, cuyo objetivo fue facilitar una mejor comprensión de la naturaleza de los nuevos paradigmas y procesos de desarrollo rural en la región latinoamericana y el Caribe.

1MSc. NOEMÍ BORJAS, Docente Universidad Nacional Autónoma de Honduras, noemi.rodriguez@unah.edu. hn, Orcid: https://orcid.org/ 0000-0001-7606-7541.

2MSc. MARTA MAZIER, Docente Universidad Nacional Autónoma de Honduras, marta.mazier@gmail.com, Orcid: https://orcid.org/ 0000-0002-2272-6756.

3MSc. MARCIA VALLADARES, Docente Universidad Nacional Autónoma de Honduras, marcia.valladares@, unah.edu.hn, Orcid: https://orcid.org/ 0000-0003-1291-4152.

4MSc. GERARDO LAGOS, Docente Universidad Nacional de Agricultura, gerardolagos85@yahoo.com, Orcid: https://orcid.org/ 0000-0003-3282-8438. 
El artículo pone énfasis en la relevancia de las concepciones contemporáneas del Desarrollo Rural Territorial (DRT), los retos que implica, y finalmente, los aspectos que deben considerarse para su abordaje actual. Como eje transversal se coloca a la gestión social como dinamizador del desarrollo rural destacando la legitimación de la participación activa de los actores territoriales.

La discusión intenta abordar la pregunta: ¿Qué falta en la gestión social territorial para lograr efectividad en el desarrollo rural en América Latina y el Caribe, y de manera particular, en los territorios de los pueblos originarios y afrodescendientes?

Se analiza el DRT desde una perspectiva integradora y sistémica, para finalizar con la propuesta de aspectos a considerar en la gestión social del desarrollo rural territorial en coherencia con los Objetivos de Desarrollo Sostenible y ante el nuevo contexto mediado por la pandemia del SARV- COV-19, con sus impactos económicos y sociales sobre el medio rural, sus implicaciones para la interacción rural-urbana y su interconexión con tendencias históricas o emergentes en las sociedades latinoamericanas.

\section{EI desarrollo rural territorial a partir de las concepciones contemporáneas de la nueva ruralidad}

El desarrollo rural con enfoque territorial toma relevancia al considerar en esta perspectiva la importancia del vínculo entre las interacciones humanas, institucionales, productivas y ambientales en la búsqueda de un desarrollo sostenible, integral y multidimensional. De manera general, este enfoque se fundamenta en los derechos humanos y en la construcción de condiciones, capacidades y oportunidades para acceder a ellos y ejercerlos efectivamente. Y dada la relevancia de las identidades colectivas y sentido de pertenencia en la construcción histórica de territorios y territorialidades, el desarrollo rural territorial se arraiga en la cultura de los pueblos y busca garantizar estados de buen vivir que legitimen la construcción de un desarrollo rural participativo e inclusivo.

Sen (2000) señala que el bienestar es el estado en que los individuos tienen la capacidad y la posibilidad de llevar una vida que tienen motivos para valorar, y esta capacidad está determinada por una diversidad de libertades instrumentales. La pregunta que surge es ¿qué tipo de vida se valora? aquella en la que la población disfrute de la capacidad para mantenerse en una buena condición física, minimizar la preocupación por la salud y garantizar el acceso a atención sanitaria; una vida con los medios de sustento asegurados y adecuados, suficientes alimentos y agua limpia en todo momento, alojamiento, vestido, acceso a energía para calefacción 


\section{DEL SILENCIO DE LAS LENGUAS NATIVAS A UN DESARROLLO RURAL TERRITORIAL}

POLÍTICAMENTE RENOVADO E INCLUSIVO

y acondicionamiento de aire y acceso a bienes naturales como los océanos, la biodiversidad, los desiertos y montañas; el suelo y subsuelo; el material genético encerrado en la naturaleza y las semillas, entre otros. Se valora más la vida cuando se tiene acceso a recursos naturales y de otro tipo y se está libre de violencia, actividades delictivas y guerras, así como seguridad frente a catástrofes naturales y las provocadas por la actividad humana. Estos aspectos evidencian la intencionalidad de asirse al concepto de libertades de Sen para profundizar sobre la teoría del desarrollo rural.

Abordar la noción del desarrollo rural territorial induce a pensar en las convergencias, diferencias y puntos de inflexión producto de la coexistencia de antiguas y nuevas formas de producción, la presencia de construcciones sociales mediadas por la cultura e identidad de las poblaciones campesinas e indígenas, su vínculo con el ambiente y la cosmovisión del desarrollo.

El desarrollo rural territorial refiere el conjunto de acciones, prácticas y disposiciones que intentan mejorar la calidad de vida de las poblaciones rurales en aspectos económicos, educativos, de salud, de infraestructura, ambientales y culturales, incrementando las posibilidades de garantizar su reproducción social y potenciar el talento humano. En esta red estratégica de relaciones, las familias agricultoras campesinas se constituyen en actores relevantes como agentes autónomos que dominan técnicas y toman decisiones sobre su modo de vivir, en un espacio que respeta su identidad cultural. Además de las familias campesinas, otros habitantes $\mathrm{y}$ actores rurales, como los migrantes, miembros de las comunidades originarias y afrodescendientes que no necesariamente se autodenominen campesinos agricultores también son esenciales.

Es desde ahí que se hace gestión y control de los procesos. La persona humana no puede concebirse como insumo, sino como el sujeto capaz de controlar y trazar sus propias alternativas de vida, no simplemente como la capacidad mecánica que le impulsará a generar ingresos. London \& Formichella (2006) sostienen que visto

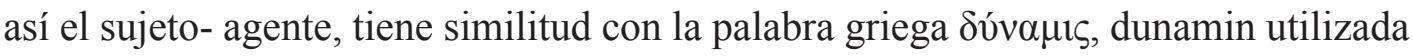
por Aristóteles en el análisis de las características humanas y que se traduce como la capacidad de existir o actuar.

Al considerar que el desarrollo es una extensión de las libertades reales que disfrutan los seres humanos, Sen nos invita a reflexionar sobre la eliminación de las principales fuentes de privación de la libertad: la pobreza, la tiranía, la escasez de oportunidades económicas, las privaciones sociales sistémicas, el abandono de los servicios públicos y la intolerancia o exceso de intervención de los Estados represivos. 
Este planteamiento teórico sobre el desarrollo fundamenta los siguientes tipos de libertad: libertad política, los servicios económicos, las oportunidades sociales, las garantías de transparencia y la seguridad protectora. Considera a dichas libertades como derechos que permiten una mejora en las capacidades de las personas. Entre los argumentos que fundamentan el análisis del desarrollo desde la perspectiva de las libertades está su importancia intrínseca, su trascendental contribución a dar incentivos políticos para proporcionar seguridad económica, y su papel constructivista en la génesis de valores y prioridades. Sen considera que el desarrollo consiste en la eliminación de algunos tipos de ausencias de libertad que dejan a los individuos pocas opciones y escasas oportunidades para ejercer el ejercicio de sus libertades.

En esencia, la tesis de Sen tiene que ver con la libertad individual como compromiso social. La expansión de la libertad es el fin primordial y, a la vez, el medio principal del desarrollo. La primera premisa está relacionada con la importancia de las libertades fundamentales para el enriquecimiento de la vida humana y adopta el papel constitutivo y la segunda que toma el papel instrumental de la libertad, se refiere a la forma en que los diferentes tipos de derechos y oportunidades contribuyen a expandir la libertad. En este sentido, aumentar las oportunidades reales que tienen las personas para mejorar sus vidas está estrechamente ligado a la calidad del medio ambiente y a la sostenibilidad de los servicios proporcionados por los ecosistemas.

Desde las nuevas perspectivas del desarrollo territorial según el Programa de las Naciones Unidas para el Desarrollo, es fundamental el involucramiento del nivel local como fuerza para impulsar un desarrollo humano más efectivo. Los territorios y las instituciones locales deberían ir más allá de la provisión de servicios y jugar un rol de actor del desarrollo para lograr resultados sostenibles. A través del enfoque territorial del desarrollo, diferentes instituciones locales y actores trabajan juntos para definir estrategias de desarrollo que reflejen una amplia variedad de intereses y prioridades a nivel local (PNUD, 2021).

En esta nueva perspectiva de desarrollo territorial como un proceso, recobra vida la multiplicidad de elementos que en él subyacen. Entre otros, el Estado con sus políticas públicas para el desarrollo rural y para la planificación del desarrollo nacional o regional; las sinergias actuales o potenciales entre los actores territoriales en la construcción de proyectos de futuro para el desarrollo de sus territorios, y el papel del mercado y del vínculo rural-urbano, implícito en este proceso. Por otra 


\section{DEL SILENCIO DE LAS LENGUAS NATIVAS A UN DESARROLLO RURAL TERRITORIAL}

POLÍTICAMENTE RENOVADO E INCLUSIVO

parte, en este enfoque se hace efectiva la apropiación social del espacio y sus partes de una manera integrada, en un entramado en el que se reconoce y respeta el ejercicio de los derechos de la población a la libertad de decisión, el cuidado y acceso a los recursos naturales, y su identidad cultural.

Es imprescindible realizar el análisis del desarrollo rural a partir del respeto de las características particulares del territorio. Para los pueblos originarios, su territorio es el espacio reproductor de cultura y donde se ejerce su autonomía, una cosmovisión con esencia espiritual, muy ligada a la naturaleza; por ejemplo, el mar para los pueblos garífunas del Caribe centroamericano, y el bosque para los misquitos en Nicaragua y Honduras.

Los pueblos originarios se sienten parte del universo, una unidad que Martucelli (2006) llama territorialidad indivisible y cosmogónica de ahí que su planificación territorial difiere totalmente de la visión occidental. Según los fundamentos de este autor, los pueblos originarios dimensionan el territorio a partir de la imaginación de sus sentidos, hasta donde la capacidad física le permite la explotación del medio y su sustento. Se trata del espacio que han compartido sus antepasados, el lugar que forma parte de su identidad y espíritu colectivo. Pero es también el espacio que les proporciona todo lo indispensable para sobrevivir como pueblos.

Y es desde esta perspectiva que la visión occidental se aleja de la cosmovisión de los pueblos originarios considerando que, aunque el enfoque territorial del desarrollo rural nace en Europa a principios de la última década del siglo pasado "la aplicación del modelo europeo trae sus dificultades, al no entrar a interpretar el sentir de las comunidades que habitan el territorio, especialmente las etnias indígenas, quienes ocupan de manera afortunada gran parte del mismo, que son consideradas reservas ecosistémicas" (Agredo, 2006). Este paradigma requiere de nuevas interpretaciones y metodologías innovadoras respecto a los derechos territoriales de los pueblos originarios y afrodescendientes, considerando la particular naturaleza de Latinoamérica y el Caribe, región que presenta realidades muy diferentes del occidente en dimensiones relevantes como la cultura, biodiversidad, la sociolingüística, política y economía.

\subsection{El territorio como noción ampliada}

La problemática que enfrenta Latinoamérica y el Caribe ha surgido, en una dimensión muy importante, por las desigualdades inter e intra territoriales y en la distribución del ingreso dentro de los países de la región y su consecuente brecha en el nivel de desarrollo entre los territorios. Las diferencias producidas por estas 
enormes desigualdades, que representan fundamentales rasgos estructurales, afectan las condiciones de vida e ingresos necesarios para alcanzar el bienestar por parte de la población rural. Esta estructura ha marcado patrones de asentamiento desde lo urbano hasta lo rural profundo, que dan lugar a territorios con dinámicas en las que sí es posible el desarrollo, pero también territorios que permanecen atrapados en profundos niveles de pobreza. Entre principios de siglo y 2019, la pobreza en general, y la pobreza rural en particular, se redujo de manera importante en algunos países como Brasil, sin que la desigualdad disminuyera de manera muy significativa en algunos países se redujo ligeramente, en otros se mantuvo y en ciertos países como Costa Rica, más bien aumentó. (CEPAL, 2016)

Al establecer comparaciones entre los territorios como distribuciones administrativas mayores, según PIB per cápita al interior de cada país a nivel mundial, la región latinoamericana presenta las diferencias más altas. Ello contrasta con la diferencia en el PIB per cápita en países pertenecientes a la Organización para la Cooperación y el Desarrollo (OCDE) que en promedio es de 1,76 y en algunos países de la región es superior a 8. Por ejemplo, la región más rica en Brasil es el Distrito Federal con 9.2 puntos sobre el Estado de Puauí, la región más pobre de ese país. Este análisis se ha realizado sobre la base de dos indicadores; por una parte se ha considerado el coeficiente de concentración territorial (que mide la distribución territorial de la actividad económica) y el coeficiente de Gini territorial (que mide la distribución de la riqueza relacionando el PIB total de cada territorio con la participación relativa de su superficie geográfica). (CEPAL, 2016)

El territorio puede ser considerado uno de los ejes estructurantes de las desigualdades sociales, porque tiene un peso determinante sobre la magnitud y reproducción de éstas en distintos ámbitos del desarrollo social. Como se ha planteado, "el lugar de nacimiento o residencia determina oportunidades y condiciones socioeconómicas, incide en la realización de los derechos políticos, económicos y sociales y puede ser una fuente de discriminación en sí, como pueden ser el género, la raza o la religión" (ILPES, 2012, pág.12). Es precisamente en el territorio donde se cristalizan, conectan y entrecruzan las desigualdades sociales analizadas en los temas anteriores y donde ocurre la reproducción intergeneracional de la pobreza. (CEPAL, 2016).Toda persona, independientemente del lugar donde nazca o resida, debe contar con las condiciones de vida y de bienestar que satisfagan sus derechos universales para garantizar su dignidad, su plena realización y el real y efectivo ejercicio de su ciudadanía, lo cual solo será posible en la medida en que haya igualdad de oportunidades. 


\section{DEL SILENCIO DE LAS LENGUAS NATIVAS A UN DESARROLLO RURAL TERRITORIAL POLÍTICAMENTE RENOVADO E INCLUSIVO}

La desigualdad, como producto de la reducción de ingresos de los hogares y el aumento de la participación del factor trabajo en el PIB han sido muy significativos en la región latinoamericana a partir del comienzo de la década de 2000. Sin embargo, según cifras de la CEPAL, en los últimos años esta situación ha disminuido. En los casos particulares de Chile, México y Uruguay, se ha presentado una mayor concentración de la riqueza que de los ingresos de los hogares. (CEPAL, 2016)

América Latina y el Caribe sigue siendo la región más desigual del mundo, con niveles de pobreza aún significativos y con amplios sectores que, si bien han superado las líneas de pobreza y extrema pobreza son cada vez más vulnerables en el campo, al incremento de la variabilidad climática, a la extracción de recursos naturales y mineros, etc. En el caso muy particular de Honduras, según datos oficiales del INE en junio de 2018 la pobreza alcanzaba a un 39,2\% de los hogares, porcentaje que en el área rural era de $46,2 \%$, en comparación con el área urbana donde era $33,8 \%$.

La Agenda 2030 para el Desarrollo Sostenible sintetiza las ambiciones de futuro para una humanidad con desarrollo sostenible. Los Objetivos de Desarrollo Sostenible (ODS) incluyen poner fin a la pobreza y el hambre en todo el mundo; combatir las desigualdades dentro de los países y entre ellos; construir sociedades pacíficas, justas e inclusivas; proteger los derechos humanos y promover la igualdad entre los géneros y el empoderamiento de las mujeres y las niñas, y garantizar una protección duradera del planeta y sus recursos naturales... (ONU, 2015)

La pobreza, éticamente intolerable y políticamente inaceptable, refleja la incapacidad de las propuestas de desarrollo para superar las inequidades y los desequilibrios. Con dificultad se abonará credibilidad a los propósitos de fomentar los valores y las instituciones democráticas en las Américas si prevalecen amplios sectores de la población excluidos de los beneficios del desarrollo. La sociedad, los gobiernos y la comunidad internacional deberían, como han acordado, atender la situación de pobreza, especialmente de la extrema pobreza, brindar oportunidades reales de acceso a las herramientas y espacios de la producción y del comercio para enfrentar, la superación de esta situación. Se trata de disminuir las disparidades económicas y sociales, favorecer el desarrollo de las capacidades humanas, de tal manera que las desigualdades alcancen rangos aceptables a la condición humana. (IICA, 1999) 
En esta construcción de desarrollo sostenible, el territorio es protagonista. Según Samper y González el concepto de territorio es polisémico "y ha generado reflexiones y debates en torno a las políticas públicas y los procesos territoriales". Se aclara con base en lo anterior, que en este documento el territorio se entenderá como una comunidad humana con sentido de apropiación y de pertenencia hacia un espacio natural y social específico. Por otra parte, hacer territorio significa construir este sentido de apropiación y de pertenencia, e implica armonizar las expectativas y necesidades del individuo con las del colectivo humano y su espacio natural y social de realización (Samper \& González, 2021)

Se ha abordado la noción de igualdad como condicionante del desarrollo territorial para enlazar el segundo criterio, la sostenibilidad, que del mismo modo que la igualdad, equidad e inclusión están en el centro de la definición de desarrollo en América Latina y el Caribe. La sostenibilidad subraya la importancia de procesos duraderos en el tiempo. Retomando los criterios anteriores y frente al modelo de desarrollo vigente, así como de las actuales relaciones entre estructuras e instituciones, podríamos preguntarnos ¿hasta dónde puede la región latinoamericana avanzar sustancialmente hacia una mayor igualdad, equidad e inclusión? La pregunta por el futuro del desarrollo es, también, la pregunta por su sostenibilidad en distintas dimensiones: política, económica, cultural, social y ambiental.

Un territorio no es solamente un espacio físico sino una construcción histórica y es también social con una identidad cultural propia. $Y$ es desde esta perspectiva que la visión occidental se aleja de la cosmovisión de los pueblos originarios en el sentido que "la aplicación del modelo europeo trae sus dificultades al interpretar el sentir de las comunidades que habitan el territorio, especialmente las etnias indígenas, quienes ocupan de manera afortunada gran parte del mismo, que son consideradas reservas ecosistémicas". (Agredo, 2006).

Estos constructos que se originan en las formas de vida compartida con sus antepasados permitiendo la formación de su identidad -multidimensional-y espíritu colectivo, son también los espacios que les proporcionan recursos indispensables para sobrevivir como pueblos. Los pueblos originarios dimensionan el territorio a partir de la imaginación de sus sentidos, hasta donde la capacidad física le permite la explotación del medio y su sustento. (Martucelli, 2006)

En las nuevas narrativas sobre territorios, sobresalen las que nacen casi de manera natural desde su interior y dan cuenta de que ya no se trata solamente de 


\section{DEL SILENCIO DE LAS LENGUAS NATIVAS A UN DESARROLLO RURAL TERRITORIAL}

POLÍTICAMENTE RENOVADO E INCLUSIVO

espacios de producción de riqueza, sino también de las expresiones socioculturales de los pueblos, sus creencias, instituciones, bienestar espiritual y su relación particular con la naturaleza que nutren al desarrollo rural. En el caso particular de los territorios indígenas, estos son conocidos como áreas poseídas en forma regular y permanente por los pueblos originarios, constituyen su hábitat o el ámbito tradicional en donde realizan sus actividades sagradas o espirituales, sociales, económicas y culturales, así otros grupos étnicos o poblacionales habiten en dicho territorio (Agredo, 2006). Es decir que el arraigo con el territorio que tienen los pueblos originarios va más allá de la concepción material; desde su visión, la ocupación del territorio se constituye en la integralidad ser humano-cosmos.

La base de la supervivencia física y cultural de los pueblos originarios radica en el reconocimiento legal y la demarcación de su territorio, lo cual se constituye en un derecho humano contemplado en el Convenio No.169 de la Organización Internacional del Trabajo (OIT), como garante del reconocimiento de sus derechos sobre las tierras y los recursos naturales. Este derecho se ve afectado por situaciones desequilibrantes de orden público, político administrativo, estrategias de gobierno, intervención extranjera, apertura económica, globalización, entre otros. Los pueblos originarios tienen derechos que se articulan alrededor de varias dimensiones entre las que tienen mayor relevancia el derecho al uso y la propiedad, acceso, uso y control de las tierras, territorios y recursos naturales, el derecho al desarrollo y al bienestar, el derecho a la integridad cultural, entre otros. (CEPAL, 2016)

\subsection{La nueva ruralidad: su contribución al desarrollo territorial}

Los planteamientos latinoamericanos sobre la Nueva Ruralidad siguen vigentes y han cobrado mayor pertinencia, hoy más que nunca. Pese a ello, los debates actuales rebasan estos enfoques y se orientan hacia el abordaje sistémico no solamente de la ruralidad sino también de la territorialidad y los territorios.

Los conceptos de territorio y territorialidad no son singulares sino plurales; hay distintas maneras de comprenderlos y su definición no puede ser solamente una normativa técnica o académica. Además de su carácter polisémico, estos conceptos son también multiescalares. La multiescalaridad, desde la perspectiva del enfoque territorial y con mayor razón si es sistémico, puede estar asociada a diversos tipos de territorios y territorialidades, que no necesariamente han de ajustarse a la división político-administrativa. La planificación regional suele obedecer a regionalizaciones variables en el tiempo que si bien pueden agrupar Estados o departamentos o provincias, son una instancia intermedia entre ellos y los gobiernos centrales, y 
no son propiamente divisiones político-administrativas. También hay territorios y territorialidades que no son zonales, sino reticulares, es decir que no corresponden a determinados espacios, sino a dinámicas de redes. Por otra parte, están las regiones o territorios funcionales, ya sea que se definan en términos socioeconómicos o abordando un conjunto más amplio de interacciones rural-urbanas y funcionalidades, y que rara vez coinciden con entidades territoriales político-administrativas.

El territorio como concepto requiere un análisis interdisciplinario en el que confluyan las ciencias sociales, las ciencias naturales y las humanidades como la antropología, la sociología, el arte, la historia, la geografía, la agroecología, la economía, y la agroeconomía, las ciencias políticas y la psicología social, la filosofía, la sociolinguística y el pensamiento sistémico, etc. áreas del conocimiento que están asociadas con los procesos transformadores de las sociedades. Aunque en sus inicios, más de sesenta años atrás, esta conceptualización se demarcaba dentro de los límites jurisdiccionales, hoy día, al extenderse hacia la dimensión social, el territorio se ha nutrido de múltiples significados.

Particularmente, el significado de autonomía desde la visión de los pueblos indígenas en el territorio se fundamenta en el principio de autodeterminación, el cual es comprendido desde la responsabilidad que implica en cuanto pertenencia. Este concepto de autonomía respecto al espacio territorial de los pueblos originarios se evidencia, por ejemplo, en las Regiones Autónomas de la Costa Atlántica de Nicaragua.

En la innovación del desarrollo rural de la región latinoamericana sobresalen los territorios que tienen una justa distribución de la riqueza natural, contraria a aquellas donde prevalecen acciones enfocadas en el extractivismo, despojando al territorio de los recursos y a la población de lograr mejores niveles de desarrollo basados en la sostenibilidad. Sassen (2007) pone en evidencia que el extractivismo no supone solamente el despojo de recursos naturales, sino que se ejerce también sobre una diversidad de seres humanos a través de los procesos intensivos de urbanización, la masificación del capital tecnológico y la acumulación financiera monopólica.

\subsection{La forestería comunitaria: indispensable para el desarrollo rural}

Latinoamérica, a pesar de aglomerar solamente $8,5 \%$ de la población mundial, está dotada de una invaluable riqueza de recursos naturales. El cuidado y preservación 


\section{DEL SILENCIO DE LAS LENGUAS NATIVAS A UN DESARROLLO RURAL TERRITORIAL POLÍTICAMENTE RENOVADO E INCLUSIVO}

de la tierra se constituye en un reto muy urgente considerando que se convierte en una clara oportunidad para la erradicación del hambre (FAO, 2015). En el mundo hay alrededor de 842 millones de personas que no tienen lo suficiente para comer. Frente a esta realidad, cuatro países latinoamericanos -Argentina, Bolivia, Brasil y Colombia- concentran 2.076 millones de hectáreas cultivables, o $12 \%$ de las tierras aptas para la agricultura. Un informe reciente del Programa de las Nacionales Unidas para el Medio Ambiente (PNUMA) indica que la región dispone de las más grandes reservas de tierra cultivable del mundo. En el caso particular de Honduras, se estima que existen 3 millones de personas viviendo en suelos de vocación forestal, y que se dedican a la realización de prácticas agrícolas de subsistencia.

Sumado a lo anterior, $23 \%$ de los bosques del planeta se ubican en Latinoamérica y el Caribe y de éstos, $46 \%$ son bosques tropicales. Los bosques latinoamericanos son refugio de diversas especies, proveedores de aire puro a la vez que producen y purifican el agua, regulan el clima, la temperatura, captan la lluvia y son grandes asimiladores de dióxido de carbono. Los bosques tropicales, selva húmeda o selva alta perennifolia protegen los suelos contra la erosión, y "los suelos saludables son la base de la agricultura, además de que son reservorios de la biodiversidad y forman parte del ciclo de carbono, por lo que es necesario cuidarlos para mitigar y enfrentar el cambio climático" (FAO, 2015). Además de poseer una importante cantidad de bosques, el $17 \%$ de las pasturas del mundo y un $19 \%$ del potencial hidroeléctrico mundial, Latinoamérica cuenta con el 31\% del agua de escorrentía. (CEPAL, 2014 ).

Para las zonas rurales donde se presentan problemas de escasez de agua y altas temperaturas producto del cambio climático y la baja humedad atmosférica, los sistemas de captación de escorrentía podrían convertirse en una alternativa para enfrentar las dificultades derivadas de la irregularidad de las lluvias, y de la falta de agua en la estación seca. En el Corredor Seco que atraviesa casi todos los países centroamericanos, por ejemplo, la disponibilidad de agua se reduce considerablemente durante la estación seca, lo que expone la vida de la población. (CATIE, 2018)

Así, el planteamiento sobre la forestería comunitaria es un modelo de gestión sostenible a partir de las condiciones actuales de América Latina en cuanto a las tierras arables, los bosques, el agua de escorrentía y el potencial hidroeléctrico. Durante 40 años del manejo forestal comunitario se ha transitado de la experimentación y desarrollo de conocimientos a la sistematización de experiencias, y se perfila como una de las alternativas para afrontar los retos de la crisis actual. Sin embargo, estas naciones enfrentan dos problemas: la tecnificación y el uso inapropiado de los terrenos. Los bosques se pierden a un ritmo del $0.7 \%$ anual; las zonas áridas cubren 
un $22 \%$ de la superficie de la región y se corre el riesgo de la desaparición de entre 100000 a 450000 especies, de continuar con las crecientes tasas de deforestación.

$\mathrm{Al}$ no ser un recurso renovable, la preservación de los suelos supone un reto muy urgente ya que "un centímetro de suelo puede demorar mil años para formarse y este mismo centímetro puede ser destruido en solamente algunos minutos por causa de degradación debido a un mal manejo". (FAO, 2014, pág. s/f) Desafortunadamente, la degradación del suelo está amenazando la mayoría de este recurso. Este fenómeno tiene un impacto negativo en muchas de sus funciones críticas para la producción de alimentos y la provisión de servicios ecosistémicos. Sus principales causas incluyen la erosión hídrica, la aplicación intensa de agroquímicos y la deforestación.

La degradación también está asociada con la pobreza: Un 40\% de las tierras más degradadas del mundo están en zonas con elevadas tasas de pobreza. Los agricultores pobres tienen un menor acceso a la tierra y al agua, trabajando suelos de mala calidad y con una alta vulnerabilidad a la degradación.

La región latinoamericana mostró una leve mejoría a nivel económico en los años 70, debido en alguna medida, a las gestiones realizadas a través de la asistencia al manejo forestal comunitario basado en experiencias y conocimientos de la población local. Estas gestiones podrían constituirse en una de las posibles alternativas para la gestión concentrada en la gobernanza de los recursos naturales, mejorando su eficacia y enlazando los territorios.

\subsection{Los Objetivos de Desarrollo Sostenible como marco orientador en el abordaje de la problemática actual del desarrollo rural territorial}

Tanto los Objetivos de Desarrollo Sostenible (ODS) como la Agenda 2030 se constituyen en una oportunidad para abrir diálogos entre los gobiernos, las empresas y las organizaciones sociales y establecer puentes que se aproximen a la atención oportuna de la multidimensionalidad de la compleja problemática actual de los territorios, especialmente de los que se encuentran en menor escala de desarrollo.

En la medida en que los diferentes actores involucrados en el desarrollo rural territorial como instancias públicas, academia, sector privado, cooperación internacional y sociedad civil establezcan sinergias de actuación se facilitará el cumplimiento de las metas comunes que corresponden a los ODS particularizados para cada territorio y hacer frente a los retos económicos, ambientales y políticos que esto conlleva.

\section{6




\section{DEL SILENCIO DE LAS LENGUAS NATIVAS A UN DESARROLLO RURAL TERRITORIAL POLÍTICAMENTE RENOVADO E INCLUSIVO}

Se debe considerar, en el abordaje del desarrollo rural territorial, el nuevo contexto mediado por los efectos e impactos de la pandemia SARS-CoV-2 (Covid-19) que afecta con mayor profundidad a territorios rurales en condiciones de vulnerabilidad. En este nuevo contexto, la limitada capacidad de respuesta ha evidenciado la fragilidad del sistema de protección social de los países de América Latina y el Caribe. Esta situación se agrava aún más por cuanto la región se caracteriza por tener "mercados laborales segmentados reproductores de desigualdades al incentivar la producción de negocios muy pequeños y poco productivos" (PNUD, 2021).

Este escenario, que pone al descubierto la alta desigualdad y el bajo crecimiento en la región, se convierte en una especie de trampa que obstruye la aproximación al desarrollo humano. Por consiguiente, el establecimiento de asociaciones inclusivas desde lo territorial puede contribuir al cumplimiento de programas de desarrollo cuya visión se oriente en función de facilitar a todos el acceso a sistemas de protección social y a más y mejores oportunidades laborales.

\section{Retos actuales del desarrollo rural}

En América Latina y el Caribe se ha promovido un enfoque de desarrollo rural basado en la apuesta por la modernización del agro, priorizando al sector campesino de pequeña y mediana explotación. Se ha visto más como una geografía con condiciones edafoclimáticas y atendiendo a un modelo agroexportador que considera el mercado como el principal fundamento donde la participación de los productores y por ende la generación del ingreso económico es capaz de revitalizar estos espacios rurales (Berdegué y Favareto 2019).

Con la creciente preocupación institucional por el ambiente, las políticas públicas han dado un giro a partir de la cumbre de Naciones Unidas celebrada en Estocolmo en 1972; el informe Los Límites del Crecimiento del Club de Roma de ese año, hace un quiebre en la forma de abordar el desarrollo que se consolida con la publicación de la Comisión Brundtland donde aparece ya el concepto de desarrollo sostenible con enfoques como la forestería comunitaria y prácticas como la agricultura agroecológica que apuestan por una agricultura más respetuosa de los recursos naturales.

En el enfoque del DTR cobran importancia, además del Estado y el mercado, los actores territoriales y el tejido social que en torno a sus relaciones se entrelazan en 
el territorio y de éste con otros; es decir, interterritorialidad. Se reconoce la diversidad de la economía rural, valorando las sinergias entre las actividades agrícolas, el empleo rural no agrícola (ERNA) y la función social que prestan los espacios naturales protegidos y sitios de interés cultural para la promoción del turismo, incidiendo en la reducción de la desigualdad y el fortalecimiento de las capacidades y los activos dentro de los territorios (CEPAL 2019).

Cada territorio debe construir una estrategia de desarrollo basada en una visión conjunta, en la cosmovisión de los pueblos originarios y de otros actores sociales, políticos e institucionales, construida desde lo endógeno, hacia la cual converjan actores cooperantes, que a través de sus recursos podrán sumar esfuerzos respetando y consultando su futuro imaginado. En tal sentido, las políticas públicas deben ser inter sectoriales y sectoriales, las primeras por las relaciones entre territorios dado que promueven las dinámicas interterritoriales y las últimas por aquellos sectores que seguirán cumpliendo funciones en cuanto a tales, educativas, de salud pública, agrícolas, etc., (Berdegué y Favareto 2019), aunque pueden y deben articularse con otras como las políticas lingüísticas, culturales y con iniciativas territoriales.

El desarrollo rural territorial presenta ciertos desafíos como producto del nuevo escenario en el que el cambio climático, la crisis económica y la pandemia SARS-Cov2 (Covid-19) actúan obstaculizando el buen vivir de los pueblos.

Se vislumbran dos concepciones sobre los desafíos en el medio rural: aquellas que tradicionalmente responden a infraestructuras o servicios que históricamente han demandado la población en el medio rural y que en países desarrollados ya no es reto, y las que han surgido a raíz de la pandemia de la SARS-Cov 2 (COVID-19) como una necesidad ante el distanciamiento que exige la crisis sanitaria, incluye el teletrabajo, la telemedicina, registro de datos digitalizados en agricultura, uso de drones, etc., que exigen a la población rural la actualización en el uso de tecnologías de información y comunicación, así como de equipos especializados para estos procesos frente a la necesidad de subsistir. La no cultura digital de muchos pueblos latinoamericanos como Honduras es un reto no solo para las zonas rurales, sino para toda la población que debe alfabetizarse en esta nueva realidad para los procesos de desarrollo.

\subsection{Desarrollo territorial rural desde la participación y consulta de actores}

Con el enfoque de DRT la dimensión económica y de transformación productiva ha sido potenciada en países como Honduras, El Salvador y Nicaragua, y 


\section{DEL SILENCIO DE LAS LENGUAS NATIVAS A UN DESARROLLO RURAL TERRITORIAL}

POLÍTICAMENTE RENOVADO E INCLUSIVO

constituye una alternativa para la puesta en ejecución de políticas públicas de lucha contra la pobreza rural y exclusión social potenciando la diversificación agropecuaria. Sin embargo, la participación de grupos vulnerables y pueblos originarios no ha sido motivada desde el Estado, el cual desde 1980 paulatinamente ha tercerizado su apoyo al agro ante la incorporación de medidas de ajuste estructural de la economía (CEPAL 2019). Muchas organizaciones de la sociedad civil se han constituido en defensores de los pueblos originarios y afrodescendientes que incluyen unidades técnicas con enfoque territorial como la MAMUGAH, la ONILH, OFRANEH y otras similares, a través de las cuales el apoyo ha continuado con mayor intensidad en los últimos años.

El DRT es un proceso que requiere de la participación y la consulta de todos los involucrados para coincidir en la visión imaginada del territorio, respetando la diversidad étnica, cultural y espiritual. Debe tener presente que pueblos originarios son fragmentados por las divisiones políticas y administrativas establecidas por las comunas y mancomunidades; en tal sentido, conviene apostar por políticas públicas supra nacionales que permitan el abordaje a dichos espacios territoriales. No obstante, el empoderamiento de los actores locales que han participado a lo largo de los proyectos y programas ejecutados en el medio rural no ha sido el deseado, bien por falta de un acompañamiento institucional a largo plazo o porque no se ha motivado la participación y los proyectos no obedecen a la priorización de sus necesidades.

\subsubsection{Relevancia de los actores territoriales en procesos de desarrollo rural}

De acuerdo con Bouckaert et al. (2010), hay tres formas principales de coordinación entre actores: las clásicas, apoyadas en instrumentos de tipo comando y control y en la jerarquía; las basadas en incentivos para que los actores cooperen; y las que se apoyan en la adhesión voluntaria de los actores a partir de mecanismos de formación de redes de complementariedad. Por lo general se espera lograr una coordinación voluntaria, en red, pero esto requiere de una identificación entre actores y la iniciativa propuesta.

Por otra parte, dentro de las posibilidades de empoderar a los actores territoriales que históricamente han estado excluidos, como los pueblos originarios, se debe potenciar a través del fortalecimiento de sus capacidades institucionales, organizacionales, de grupos y también individuales de quienes participan y toman decisiones en los territorios, siendo necesario la implementación de programas formativos. 
La inserción o empoderamiento de actores territoriales requiere de formación acorde con las necesidades identificadas para luego concertar y permitir el intercambio de experiencias exitosas a través de la implementación de planes, programas y proyectos.

\subsubsection{Las capacidades técnicas y políticas en los actores rurales}

Como señalan Pires y Gomide (2013), las capacidades técnicas son importantes para introducir nuevos contenidos en la acción pública, y las capacidades políticas son fundamentales para que esa innovación tenga un alcance masivo. Si se movilizan exclusivamente capacidades técnicas, sin las capacidades políticas, las innovaciones se quedan localizadas, aisladas, limitadas a contextos acotados. Son necesarias las capacidades políticas para tener la fuerza de cambiar los marcos generales y alzar dichas innovaciones a un nivel de cambio en las reglas del juego que organizan las interacciones entre los actores de un territorio y de múltiples territorios en cada país. La capacidad política es necesaria para el escalamiento vertical (a través de políticas, programas, etc.) y también para facilitar el escalamiento horizontal de innovaciones, en este caso de gestión social del Desarrollo Territorial.

El fortalecimiento y capacidad de diálogo entre actores territoriales es crucial, y también es preciso mejorar la capacidad de negociación y mediación de conflictos. Los gobiernos locales, mancomunidades, pueblos originarios y vulnerables, redes y sociedad civil, empresas privadas y cooperativas la requieren para gestionar los diferentes intereses existentes y la discusión de diversas agendas, logrando consensos y así evitar que haya captura por intereses específicos.

Es fundamental fortalecer el diálogo y lograr que todos los actores territoriales puedan llegar a consensos donde grupos de campesinos, gobiernos locales, grupos indígenas y mancomunidades, entre otras instancias $\mathrm{u}$ organizaciones, puedan involucrarse para la gestión y ejecución de planes, programas y proyectos a corto, mediano y largo plazo.

Se requiere de arreglos institucionales compatibles con la legislación que gobierna los recursos públicos en los países, que permitan que los actores territoriales no solo sean consultados y puedan aconsejar o proponer (o presionar), sino que puedan decidir, en ese proceso de territorialización de las políticas públicas, ser responsables de la asignación y uso de fondos públicos (Berdegué y Favareto, 2019). Por lo tanto, 


\section{DEL SILENCIO DE LAS LENGUAS NATIVAS A UN DESARROLLO RURAL TERRITORIAL}

POLÍTICAMENTE RENOVADO E INCLUSIVO

es necesario que la capacitación y formación sea constante para empoderar a los actores territoriales y así puedan ser parte del proceso y tomar las mejores decisiones logrando el desarrollo en sus territorios.

\subsection{Coordinación sectorial e intersectorial y los objetivos de desarrollo sostenible}

En algunos países latinoamericanos, por ejemplo en Honduras, el desarrollo rural territorial se ha visto focalizado, asignándose al Ministerio de Agricultura, y posteriormente a través de la Secretaría de Estado en los Despachos de Desarrollo Comunitario, Agua y Saneamiento (SEDECOAS), debe ser transversal, considerando que otros ministerios pueden aportar desde sus esferas de competencia como infraestructura, ambiente, finanzas, etc. Los planes de desarrollo rural deben ser lógicos en cuanto a actividades y presupuestos, y su ejecución canalizada hacia las alcaldías municipales agrupadas en mancomunidades para no perder la visión inter territorial acompañados de sistemas de documentación para el seguimiento en el tiempo.

Además, existe escasa coordinación entre niveles de gobierno con actores privados, no gubernamentales y públicos, y entre estos y actividades agrícolas y no agrícolas, urbanas y rurales por cuanto urge de instrumentos de concertación y de coordinación que impulsen una agenda de visión compartida que consideren la cosmovisión local, las ventajas comparativas y libre empresa, y el uso de los recursos naturales desde el consenso local (Berdegué y Favareto 2019).

La agenda 2030 y los 17 Objetivos de Desarrollo Sostenible (ODS) contribuyen a que el enfoque de desarrollo territorial en el mundo rural demande la articulación intersectorial de las 169 metas de los ODS. De estas, 36 metas deben realizarse en territorios rurales, y con el ODS № 17 se persigue la creación de alianzas para el desarrollo sostenible. Así, podría existir la vinculación del enfoque DRT con la Agenda 2030 y los ODS que debe estar a tono con el crecimiento económico y bienestar de cada país.

\subsection{Incorporación de bienes y servicios del medio rural a plataformas tecnológicas}

La pandemia del SARS-CoV-2 (Covid-19) está marcando un nuevo hito en la historia de la humanidad y que más adelante se podrá determinar con mayor claridad; uno de esos cambios es el empuje hacia la automatización de procesos con el propósito de evitar la aglomeración de personas y en el caso de las relaciones comerciales se aceleró el uso de plataformas para la realización de transacciones comerciales ante el temor del uso de dinero en efectivo por el miedo al contagio, como ha sucedido 
en Latinoamérica. , y Ante la necesidad de dinamizar la economía en el medio rural se aceleró la adopción de aplicaciones móviles que conectan usuarios con diferentes servicios.

Aún hay camino por recorrer en Latinoamérica y el Caribe. Sin embargo, el medio rural deberá apuntar a estrategias y programas de desarrollo de sus territorios donde el uso de la tecnología garantice, a través de la trazabilidad de cada cadena de valor, el origen de bienes y servicios asociados con buenas prácticas agrícolas y respetuosas del medio ambiente.

Los medios rural y urbano constituyen un tejido de relaciones que van más allá de la esfera productiva o económica. La ciudad demanda productos primarios y servicios ambientales provistos en su mayoría por el medio rural, en tanto lo rural recibe servicios y productos con valor agregado que no poseen sus habitantes. La ciudad manifiesta su influencia sobre el medio rural con una intensidad que decrece con la distancia, como lo explica (Navarro-Rodríguez, 1998) de tal manera que los asentamientos alejados constituyen el medio rural profundo donde es notoria la intensidad de la relación hombre -naturaleza. En Latinoamérica este espacio rural profundo se caracteriza por el bajo grado en el que la población goza de los servicios especializados y productos transformados en comparación con sobre todo con el medio rural-urbano y peri-urbano.

En este sentido, cobra relevancia la necesidad del ordenamiento del territorio, de sus espacios naturales protegidos, y la definición de la vocación productiva de cada región. Se requiere de atención diferenciada a las necesidades de lo rural, y de los distintos tipos de ruralidad, según su grado de alejamiento o de cercanía de la ciudad o sus vinculaciones con ella. También son necesarias políticas públicas que viabilicen efectivamente el dinamismo en estas territorialidades.

\subsection{Articulando lo rural -urbano y la relación con la naturaleza}

Lo rural y lo urbano están entrelazados y su interdependencia deberá ser considerada en la formulación de las políticas públicas. Por lo común, la formulación de políticas de desarrollo rural o ha sido enfocada en exclusivamente en el campo, específicamente en la dinamización del agro, sin considerar la interacción ruralurbana. Esta última se refiere a los flujos ecosistémicos y de energía; económico y laborales, de bienes y servicios, como también culturales y de información entre los centros urbanos y rurales. En tal sentido, Berdegué y Favareto (2019) proponen expandir el concepto de lo rural incorporando las ciudades pequeñas y medianas, lo 


\section{DEL SILENCIO DE LAS LENGUAS NATIVAS A UN DESARROLLO RURAL TERRITORIAL}

POLÍTICAMENTE RENOVADO E INCLUSIVO

cual multiplica los actores, actividades económicas e instituciones en la dinámica del territorio y el rompimiento de la concepción de lo rural como ámbito circunscrito exclusivamente al campo y la naturaleza.

Los territorios rurales, distanciados actualmente de los urbanos en términos de planificación y programación de acciones vinculantes, urgen de estrategias y medidas traducidas en acciones tangibles acordes largo plazo con los ciclos políticos de los gobiernos nacionales y locales. Estas deben plantearse como senderos con puntos clave o metas a corto y mediano plazo donde habrá que medirse el nivel de avance hacia la visión compartida de los actores, requiriendo la movilización de recursos técnicos y financieros de forma constante y sostenida.

Existen asimetrías entre los actores territoriales y lugares denotando el deplorable posicionamiento del medio rural ante la ciudad, debido a la migración, especialmente de la población en edad de trabajar por la incipiente dotación de infraestructuras sociales y productivas que permiten la generación de ingreso. Ante ello se hace necesario el un modelo de economía y desarrollo que esté basado en los poten $\neg$ ciales endógenos de los propios territorios (Lee y Delgadillo 2019).

\section{Aspectos a considerar en propuestas de gestión social del desarrollo rural territorial}

Los aspectos que aquí se plantean se han construido desde una perspectiva crítica y constructiva, basándose en el análisis de las experiencias en América Latina y el caribe y en particular, el caso de Honduras. Este país ha recibido importantes inversiones en materia de desarrollo rural y sin embargo, la deuda social se agranda, ya que lejos de observar mejoras significativas, la sociedad experimenta conflictos que van desde acciones colectivas sociales para enfrentar el despojo de los recursos naturales (suelo y bosque), hasta violencias territoriales, desde asesinatos y desapariciones de líderes y lideresas por la defensa de los recursos naturales: a lo que se agrega la falta de empleo digno, entre otros, que conducen a las personas a migrar; flujos migratorios- ahora no solo de jóvenes-, de familias completas, que no ven en sus lugares oportunidades para mejorar la calidad de vida.

Los aspectos priorizados en las propuestas de gestión social del desarrollo rural territorial están relacionados con la identidad cultural, los derechos humanos y la inclusión social, lo anterior, en vínculo estrecho con los actores territoriales, internos y externos como tomadores de decisiones. Las oportunidades de desarrollo rural territorial están mediadas por el tipo de gestión social y las características de las relaciones que se establecen en el tejido organizativo e institucional. 
Para comprender los aspectos que se plantean para el desarrollo rural territorial en este artículo, es necesario aclarar en qué tipo de gestión social se está pensando. Ésta se aborda como gobernanza de los territorios rurales basada en la participación con decisión política e inclusiva de los actores territoriales principalmente los de las organizaciones sociales, que residen permanentemente en él, y que es en quienes recaen las acciones de desarrollo que se impulsan por lo general desde actuaciones institucionales externas. Así, "las representaciones que se asocian con él y las prácticas que implica varían radicalmente según se adopte el punto de vista del "desarrollador", comprometido en hacer llegar la felicidad a los demás, o el del "desarrollado", obligado a modificar sus relaciones, sociales y con la naturaleza, para entrar en el mundo nuevo que se le promete" (Burbano C, 2011).

La gestión social del desarrollo, así entendida, se plantea desde el territorio, donde intervienen múltiples actores o agentes del desarrollo (multi actores), cada uno con sus propias necesidades, motivaciones, prioridades, agendas y tiempos: de base comunitaria, municipales, los de la institucionalidad pública central y los externos, como la cooperación internacional al desarrollo. Estos diversos actores convergen en realidades complejas, con intereses distintos y muchas veces contra opuestos que generan conflictos; en este sentido, es importante que la gestión social pueda hacer que se pongan sobre la mesa los diversos intereses, que se negocien y se canalice constructivamente la conflictividad.

Por otra parte, cuando la gestión social del territorio rural se construye desde la participación de los actores del territorio, las probabilidades de generar procesos de desarrollo rural sustentables y sostenibles son mayores; en el primer caso, lograr procesos de desarrollo rural que trasciendan la temporalidad establecida en planes, programas y proyectos, hacia la gestión autónoma y comprometida de los actores territoriales; en el segundo caso, la sostenibilidad pensada en el uso ético, responsable y equitativo de los recursos naturales y de cualquier acción que comprometan la sostenibilidad de ecosistemas, por ejemplo. De esto dan cuenta casos en América Latina, como el distrito de Rafaela en Argentina con el programa Rafaela Sustentable que promueve estrategias territoriales para el uso racional de los recursos "conservando su capacidad de regeneración natural, la producción más limpia y el uso de energías renovables, eficientes y descentralizadas", asegurando así la sostenibilidad. En este programa, la alianza entre el sector público, el privado, el sistema científico tecnológico y la comunidad son parte de la estrategia de concertación y sostenibilidad de la gestión social del territorio (Programa de Gestión de la Ciudad, 2011). 
La fortaleza de casos como el de Rafaela y otros en Latinoamérica, radica en tejidos sociales e institucionales que establecen francas alianzas, en las que se trata de ganar-ganar y "se percibe como un proceso en constante evolución que se nutre de la voluntad de los actores de participar activamente en la gestión de los espacios (territorios) y de las administraciones locales. El territorio aparece, entonces, como una entidad activa que alcanza su potencial de desarrollo a través de sus recursos locales, entendidos en sentido amplio, es decir, con sus actividades, sus actores, sus redes, etc." (FAO, 2016).

\subsection{La identidad cultural en el desarrollo rural territorial}

La noción de territorio como ya se ha venido exponiendo, no se limita simplemente a una porción de tierra, sino que también es una construcción histórica, social y política. En el territorio la identidad cultural marca y determina los procesos de desarrollo, porque no hay territorio sin su propia identidad -en unos más arraigada que en otros-. Aun así, estos procesos tienen que ver con la existencia de la vida humana y con la coexistencia y relacionamientos con sistemas biológicos multidiversos.

La identidad cultural es determinante en cualquier gestión social del desarrollo rural territorial y debe ser tomada en cuenta como parámetro para la toma de decisiones políticas y legitimar los procesos de desarrollo, mejorar la cohesión en los territorios y facilitar la acción colectiva territorial.

Fonte y Ranaboldo, haciendo referencia al ensayo de Olga Lucía Molano, señalan que: "El concepto de identidad cultural implica un sentido de pertenencia a un grupo social con el cual se comparten rasgos culturales, como costumbres, valores y creencias. La identidad no es un concepto fijo, sino que se recrea individual y colectivamente y se alimenta de forma continua de la influencia exterior. ... Aunque el concepto de identidad trascienda las fronteras (como en el caso de los emigrantes), el origen de este concepto se encuentra con frecuencia vinculado a un territorio" (Fonte \& Ranobaldo, 2008).

En esencia, la identidad cultural está íntimamente ligada al sentido de pertenencia de la población con su historia, su modo de vida y su relación con el entorno social, natural y espiritual. Promover una gestión social basada en el respeto a la identidad cultural de los territorios, permitirá: 
-establecer confianza y respeto mutuo entre los actores que intervienen en los procesos de desarrollo rural;

-generar las bases de construcciones democráticas y participativas;

- la gobernanza sostenible e inclusiva de los procesos de desarrollo rural territorial, que contribuyen a la continuidad de las acciones, una vez que los actores institucionales finalizan sus tiempos de ejecución de programas, proyectos o cualquier otra iniciativa;

- construir una cultura de paz y reducir o canalizar constructivamente el conflicto territorial, de tal manera que estos antagonismos se vuelvan oportunidades de desarrollo en las que los territorios eleven su capacidad competitiva y en general una gestión social dialogada y consensuada.

La gestión social con identidad cultural, como dinamizador de las distintas iniciativas del desarrollo rural territorial, no puede concebirse desde la perspectiva unilateral de los tomadores de decisiones, sea en el ámbito público, privado, de la sociedad civil o de la cooperación al desarrollo. Pensar el desarrollo desde el ideario del diseñador de procesos de planificación -estrategias, programas o proyectos-, sin considerar el contexto cultural e identitario del territorio, es desconocer la relevancia de éste en la eficacia del desarrollo, de sus resultados, impactos y sostenibilidad.

Este aprendizaje del entorno cultural no solo debe ser relativo a las prácticas ancestrales de los pueblos en algún tema específico, sino también a la gestión social efectuada en el desarrollo rural territorial. Cabe preguntarse ¿por qué ciertas gestiones sociales territoriales no logran sus objetivos en un lugar y en otros sí? En todo caso, cultura significa saber milenario y saber contemporáneo a través de las prácticas acumuladas en el tiempo. De esas experiencias y aprendizajes que pueden ser exitosos o no, es necesario cuestionarse qué parte de la cultura es determinante para que la gestión social del desarrollo rural territorial logre el propósito.

"La gestión social surge, de un proceso de evolución de técnicas, metodologías en el contexto latinoamericano con la implementación de políticas públicas, para lograr el crecimiento, la equidad, la sostenibilidad y la competitividad sistémica" (Barajas \& Tobón, 2019).

Si no se considera en el diseño de las acciones del desarrollo rural territorial a la cultura como referente de base, las posibilidades de lograr la eficiencia de la inversión y la sostenibilidad de los procesos serán menores que aquellas donde se consideraron las costumbres, lengua nativa, idearios colectivos de los pueblos, formas de gobernanza, entre otros aspectos. 


\section{DEL SILENCIO DE LAS LENGUAS NATIVAS A UN DESARROLLO RURAL TERRITORIAL}

POLÍTICAMENTE RENOVADO E INCLUSIVO

En esta propuesta será determinante la simbiosis académica en la aplicación de estudios que integren diferentes disciplinas como la antropología, la sociología, la biología, la historia, la sociolingüística, la agronomía, y cuyos resultados sirvan de base para la caracterización territorial y aproximar una eficiente gestión social del territorio rural. Serán fundamentales buenas relaciones de gobernanza con participación tanto del Estado como de la sociedad civil para efectuar el desarrollo rural, bajo el entendido que los actores territoriales, con intereses contrapuestos o afines, trabajan por un objetivo común: el desarrollo del territorio rural.

\subsection{EI enfoque de derechos humanos e inclusión ante los Objetivos de Desarrollo Sostenible y la agenda 2030}

La relación entre la libertad individual y el desarrollo social va más allá de la conexión constitutiva, por importante que ésta sea. Lo que pueden conseguir positivamente los individuos depende de las oportunidades económicas, las libertades políticas, las fuerzas sociales y las posibilidades que brindan la salud, la educación básica y el fomento y el cultivo de las iniciativas. (Sen A. , 2000).

La gestión social que toma como referente el pensamiento filosófico de Amartya Sen, sin duda estará en la búsqueda de un mundo rural equilibrado y justo; es decir un todo sistémico y armónico. Éste requiere de relaciones igualitarias en la interacción de las personas, organizaciones e instituciones que conviven en un territorio determinado y el mundo que habita. Esto significa que dichas personas o entidades tienen capacidad de decidir lo que les conviene o no; tienen libertad de pensar y actuar en su desarrollo presente y posterior.

En la gestión del territorio rural los derechos humanos deben constituirse en la plataforma que guíe cualquier acción de desarrollo. Ya en la década de los ochenta, la Organización de las Naciones Unidas establecía que el ser humano debe ser el centro de todas las acciones y que debe participar en condiciones de respeto a sus derechos y libre determinación, "El derecho al desarrollo es un derecho humano inalienable en virtud del cual todo ser humano y todos los pueblos están facultados para participar en un desarrollo económico, social, cultural y político en el que puedan realizarse plenamente todos los derechos humanos y libertades fundamentales, a contribuir a ese desarrollo y a disfrutar del él” (ACNUDH, 2021).

La gestión social en el desarrollo territorial que aquí se propone no es solo una apuesta a la reconstrucción, inclusión y aprovechamiento inteligente de lo que la ruralidad históricamente ha ofrecido; es también un espacio para reestablecer los derechos humanos desde un enfoque de participación ciudadana, justicia y sostenibilidad de los recursos y la soberanía alimentaria para un mundo mejor. 
En la ruralidad la gestión social bajo cualquier modelo de desarrollo debe respetar la identidad cultural como derecho de los pueblos, la participación y libertad de expresar sus razonamientos y propuestas sobre aquellas intervenciones que de una $\mathrm{u}$ otra manera comprometan su bienestar.

La gestión social efectiva en los territorios será posible cuando haya decisión política del tejido institucional público, privado y de la sociedad civil. Lo anterior, para alinear y armonizar las estrategias y cualquier acción de desarrollo, estableciendo parámetros que tienen que ver con las características específicas de cada territorio, con sus intereses, recursos y cosmovisiones.

Cuando se establezca consenso entre los actores territoriales para las decisiones sobre su desarrollo presente y futuro, podrá evitarse lo que Bartra ya ha reflexionado sobre las redes imaginarias de poder que por un lado legitiman a quienes se adhieren a sus modelos y por otro lado excluyen a quienes no se apegan a éstos. (Bartra, 2013) Este consenso pasa por el respeto a la libertad de expresión y la relevancia del uso y revitalización de las lenguas nativas como vehículo de comunicación principal con su carácter creador y de conservación del conocimiento ancestral y que marca formas de entendimiento en quienes la usan para aprehender su realidad y tomar decisiones que competen a su vida.

El derecho a decidir conlleva a tomar decisiones asertivas de inclusión social, no como mero discurso, sino como una exigencia para el desarrollo desde un enfoque sostenible, inclusivo y participativo. En este aspecto es importante el papel de las mujeres, en sus luchas cotidianas y en la acción colectiva; las mujeres que histórica y ancestralmente han estado dedicadas a la economía del cuidado y a la protección y defensa de los recursos naturales y la identidad cultural. En el caso de Honduras, por ejemplo, las mujeres en los territorios rurales han jugado un papel determinante durante la pandemia, en la promoción de medidas de prevención y atención a partir de medicina natural ancestral en sus comunidades rurales; de igual manera, sosteniendo y reactivando los sistemas agroalimentarios familiares que en este contexto ha permitido llevar alimento a los hogares y generar algún tipo de economía local.

El COVID-19 ha profundizado las desigualdades sociales, expresadas en un insuficiente acceso a servicios de salud oportunos y de calidad, rezago educativo por la falta de acceso a tecnologías de información y crisis en las economías rurales- e infraestructura adecuada, disponibilidad de crédito y asistencia técnica. Sin embargo, 
"la actual crisis ha permitido un mayor control y gestión democrática del territorio, convirtiendo a los territorios en espacios de vida basados en relaciones de solidaridad y colectividad, alrededor de una ola de resignificación humana y ética que está construyendo un tejido social comunitario con fuerte sentido democrático y creador de alternativas”. (López, 2020, pág. 82)

La inclusividad y sostenibilidad sí son posibles y necesarias en el desarrollo rural territorial para alcanzar relaciones mancomunadas, dialogadas y negociadas "no sólo por la necesidad de ofrecer respuestas concretas y eficaces al conjunto de la población local, sino por la insuficiencia o limitaciones de las políticas centralistas y sectoriales y de los viejos enfoques asistencialistas de la política de desarrollo regional y de la política social" (Alburquerque, 2004).

Desde una mirada crítica de diferentes procesos de gestión, las oportunidades de actuación de los actores y la relevancia de generar desarrollo humano sostenible, cuyo centro es el cuidado de los recursos naturales y la sobrevivencia humana, se constituyen en una cultura universal de buen vivir. En este entendido, trascender el ámbito de lo nacional es fundamental; el caso de la integración centroamericana es determinante para mejorar complementariedades de manera regional, aprovechando la iniciativa de la ECADERT para construir consensos y superar las falencias que la gestión social del desarrollo rural ha mostrado. "Es cada vez más necesario, pero no ha resultado fácil, incorporar cabalmente el enfoque territorial sistémico, integral, participativo y multiescalar en las políticas para el desarrollo de los territorios rurales en América Latina, desde su formulación y diseño hasta su implementación, seguimiento y auditoría social” (Samper, 2020).

Lograr estas relaciones en condiciones de inclusión rural territorial, con enfoques de sostenibilidad y ética productiva no solo favorecerá a territorios específicos sino a la humanidad y al planeta en general. En este sentido, el desarrollo humano no estará mediado solo por lógicas económicas sino por indicadores cuyo centro es el ser humano en perfecta armonía con la naturaleza.

¿Pueden imaginar un mundo en el que se entienda la naturaleza como un conjunto de elementos relacionados entre sí y no de recursos, en el que los derechos inalienables lleven aparejadas responsabilidades también inalienables y la propia riqueza no se mida a través de la propiedad de los recursos y el control sobre éstos, sino por el número de buenas relaciones que mantenemos en los complejos y diversos sistemas vitales de este planeta verde y azul? Yo sí puedo. (PNUD, 2020). 


\section{BIBLIOGRAFÍA}

ACNUDH. (2021). (ACNUD, Editor) Recuperado el mayo de 2021, de Organización de las Naciones Unidas Oficina del Alto Comisionado: https://www.ohchr.org/sp/ professionalinterest/pages/righttodevelopment.aspx

Agredo, G. (julio de 2006). El TERRITORIO Y SU SIGNIFICADO PARA LOS PUEBLOS INDÍGENAS. Luna Azul(23), 5. Recuperado el 2021

Alburquerque, F. (abril de 2004). Desarrollo económico local y descentralización. (82), 170.

Barajas, M., \& Tobón, A. (2019). Estado del Arte del Concepto Gestión Social, Características y Aplicabilidad en el Contexto latinoamericanos. Valmaria, Colombia. Tesis, UNIMINUTO, Valmaria, Colombia.

Bartra, R. (2013). Territorios del Terror y la Otredad. México, México: Siglo XXI.

Bouckaert, P. y. (2010). he coordination of public sector organizations: shifting patterns of public management. Londres: Palgrave MacMillan.

Burbano C, A. (2011). Desarrollo Local: Manual Básico para Agentes de desarrollo local. Malaga, España.

CATIE. (2018). Diseño de sistemas de captación de escorrentía. Managua.

CEPAL. (2014 ). Recursos naturales: situación y tendencias para una agenda de desarrollo regional en América Latina y el Caribe".

CEPAL. (2016). La matriz de la desigualdad social en América Latina. Naciones Unidas, Santiago, Chile.

CEPAL. (2019). Planificación para el desarrollo territorial sostenible en América Latina y el Caribe. Santiago de Chile.

CEPAL. (2020). "Los pueblos indígenas de América Latina -Abya Yala y la Agenda 2030 para el desarrollo sostenible: Tensiones y dasafíos desde una perspectiva territorial”. Sntiago: Documentos de proyectos(LC/TS.2020/47).

Cooperación, I. I. (2020). La nueva Ruralidad. Panamá. 


\section{DEL SILENCIO DE LAS LENGUAS NATIVAS A UN DESARROLLO RURAL TERRITORIAL}

POLÍTICAMENTE RENOVADO E INCLUSIVO

De Sousa, B. (2003). La caída del Angelus Novo. Ensayos para una nueva teoría social y una nueva p'ractica política. Capítulo 5 Desigualdad, exclusión y globalización: hacia la construcción multicultural de la igualdad y la diferencia, colección Clave del Sur. Colombia: ILSA.

FAO. (2014). América Latina y el Caribe lanza el Año Internacional de los Suelos 2015. Recuperado el 10 de junio de 2021

FAO. (2015). Los suelos sanos son la base para la producción de alimentos saludables. Roma, Italia. Recuperado el 10 de junio de 2021

FAO. (2016). Desarrollo Territorial, innovación y comunicación: Hacia un apoyo integado a la agricultura familiar. Brasilia: FAO.

Fonte, M., \& Ranobaldo, C. (junio de 2008). Desarrollo rural, territorios e identidades culturales. perspectivas desde américa latina y la unión europea. (Opera, Ed.) 7(7), 31-99.

GOMIDE, A., \& PIRES, R. R. (2014). Capacidades estatais e democracia: arranjos institucionais de políticas públicas. Brasília: Ipea, 2014.

IICA. (1999). El Desarrollo Rural Sostenible en el marco de una nueva lectura de la ruralidad. IICA, Panamá. Recuperado el 28 de junio de 2021, de https://repositorio. iica.int/handle/11324/9879

INE. (2018). LXI ENCUESTA PERMANENTE DE HOGARES DE PROPÓSITOS MÚLTIPLES . Tegucigalpa.

Llungo, J. (2018). Desigualdades y políticas regionales en América Latina: una visión actual. nvestigaciones Regionales-Journal od Regional Research,41(41), 11-51.

London, S., \& Formichella, M. M. (enero-junio de 2006). El concepto de desarrollo de Sen y su vinculación con la educación. Redalyc, XI, 17.32. Obtenido de https:// www.redalyc.org/articulo.oa? id $=51001702$

López, B. (2020). Honduras: Alternativas comunitarias que le hacen frente a la pandemia del COVID-19. Tegucigalpa: CESPAD. Recuperado el 25 de junio de 2021

Martucelli. (2006). Lo intercultural en acción, identidades yemancipaciones. Interculturalidad y globalización: el desafío de una poética de la solidaridad. 
Navarro-Rodríguez, S. (1998). La dependencia de los espacios rurales profundos: observaciones sobre la provincia de Málaga. Universidad de Málaga. Málaga: Facultad de Filosofía y Letras. Recuperado el 25 de junio de 2021, de https://riuma.uma.es/ xmlui/bitstream/handle/10630/9398/10\%20NAVARRO\%20RODR\%c3\%8dGUEZ. pdf? sequence $=1$ \&isAllowed $=\mathrm{y}$

ONU. (2015). "Transformar nuestro mundo: la Agenda 2030 para el Desarrollo Sostenible". Nueva York.

PNUD. (2020). Informe sobre Desarrollo Humano 2020 La próxima frontera el desarrollo humano y el antropoceno. Nueva York: PNUD.

Programa de Gestión de la Ciudad. (2011). Café de las ciudades. Recuperado el ju de 2021, de Cafedelasciudades.com.ar: https://cafedelasciudades.com.ar/ambiente_109. htm

Samper, M. (2019). Desarrollo rural con enfoque territorial en América Central. San José, Costa Rica. Recuperado el 5 de octubre de 2020, de https://www.researchgate. net/publication/343415211_Desarrollo_rural_con_enfoque_territorial_en_America_ Central_-_Perspectiva_regional_y_experiencias_nacionales_Aprendizajes_ Desarrollo_rural_con_enfoque_territorial_en_America_Central

Samper, M. (diciembre de 2020). Aprendizajes de experiencias latinoamericanas en gestión social del desarrollo territorial:Reflexiones e implicaciones conceptuales. (IICA, Ed.) Cuaderno de Trabajo sobre Inclusión(20), 137.

Samper, M. (diciembre de 2020). Aprendizajes de experiencias latinoamericanas en gestión social del desarrollo territorial:Reflexiones e implicaciones conceptuales. (IICA, Ed.) Cuaderno de Trabajo sobre Inclusión(20), 137.

Samper, M., \& González, H. (. (2021). Recuperado el 27 de junio de 2021, de https:// repositorio.iica.int/.

Samper, M., \& González, H. (27 de junio de s/f). (IICA, Ed.) Obtenido de https:// repositorio.iica.int/

Samper, Mario; González, Hernán. (SF). https://repositorio.iica.int/. (IICA, Ed.) Recuperado el 27 de junio de 2021

Sassen, S. (2007). Sociología de la globalización. Buenos Aires: Katz.

Sen, A. (2000). Desarrollo y Libertad. Barcelona, España: Sen, A. (2000). Desarrollo 
y Libertad (Primera Edición ed.). (E. Planeta, Ed., \& E. R. Toharu, Trad.) Barcelona, España: Planeta.

Serrano, A. (noviembre de 2018). Tegucigalpa, Honduras.

\section{CÍRCULO TEMÁTICO: DESARROLLO RURAL}

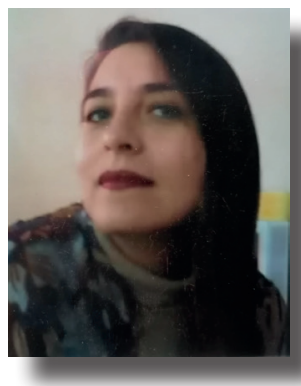

Noemí Borjas

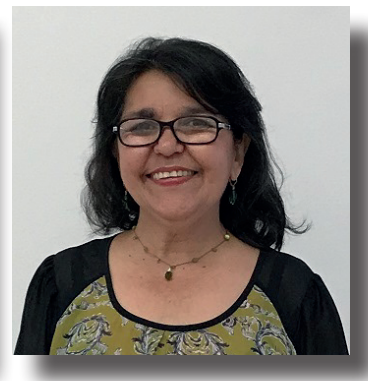

Marta Mazier

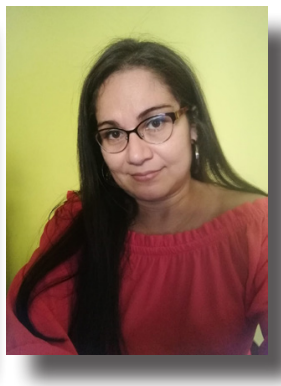

Marcia Valladares

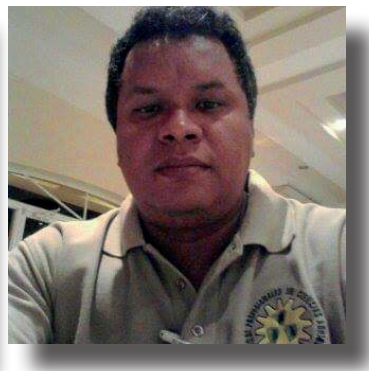

Gerardo Lagos 